Please cite this article in press as: Stevenson CW, et al., Early life programming of hemispheric lateralization and synchronization in the adult medial prefrontal cortex, Neuroscience (2008), doi: 10.1016/j.neuroscience.2008.06.013

Neuroscience $\mathrm{xx}(2008) \mathrm{xxx}$

\title{
EARLY LIFE PROGRAMMING OF HEMISPHERIC LATERALIZATION AND SYNCHRONIZATION IN THE ADULT MEDIAL PREFRONTAL CORTEX
}

\author{
C. W. STEVENSON, ${ }^{a *}$ D. M. HALLIDAY, ${ }^{b}$ \\ C. A. MARSDEN ${ }^{\mathrm{a}}$ AND R. MASON ${ }^{\mathrm{a}}$ \\ aschool of Biomedical Sciences, University of Nottingham, Queen's \\ Medical Centre, Nottingham, NG7 2UH, UK \\ ${ }^{b}$ Department of Electronics, University of York, York, YO10 5DD, UK
}

\begin{abstract}
Neonatal maternal separation (MS) in the rat increases the vulnerability to stressors later in life. In contrast, brief handling $(\mathrm{H})$ in early life confers resilience to stressors in adulthood. Early life programming of stress reactivity may involve the medial prefrontal cortex (mPFC), a region which modulates various stress responses. Moreover, hemispheric specialization in MPFC may mediate adaptive coping responses to stress. In the present study, neuronal activity was examined simultaneously in left and right MPFC in adult rats previously subjected to MS, $\mathrm{H}$ or animal facility rearing (AFR). In vivo electrophysiology, under isoflurane anesthesia, was used to conduct acute recordings of unit and local field potential (LFP) activity in response to systemic administration of $\boldsymbol{N}$-methyl- $\beta$-carboline-3-carboxamide (FG-7142), a benzodiazepine receptor partial inverse agonist which mimics various stress responses. MS decreased basal unit activity selectively in right MPFC. Basal LFP activity was reduced with MS in left and right MPFC, compared to AFR and $H$, respectively. Hemispheric synchronization of basal LFP activity was also attenuated by MS at lower frequencies. FG7142 elicited lateralized effects on MPFC activity with different early rearing conditions. Activity in left MPFC was greater with AFR and MS (AFR $>M S$ ), whereas activity was predominantly greater with $\mathrm{H}$ in right mPFC. Finally, compared to $A F R$, MS reduced and $H$ enhanced hemispheric synchronization of LFP activity with FG-7142 treatment in a dose-dependent manner.

These results indicate that functionally-relevant alterations in mPFC GABA transmission are programmed by the early rearing environment in a hemisphere-dependent manner. These findings may model the hemispheric specialization of MPFC function thought to mediate adaptive coping responses to stressors. They also suggest the possibility that early environmental programming of hemispheric functional coupling in $\mathrm{MPFC}$ is involved in conferring vulnerability or resilience to stressors later in life. (c) 2008 IBRO. Published by Elsevier Ltd. All rights reserved.
\end{abstract}

Key words: asymmetry, functional connectivity, handling, laterality, maternal separation, stress.

${ }^{*}$ Correspondence to: C. W. Stevenson, Leicester School of Pharmacy, De Montfort University, Hawthorn Building, The Gateway, Leicester LE1 9BH, UK. Tel: +44-116-207-8117; fax: +44-116-257-7287. E-mail address: carlwstevenson@googlemail.com (C. W. Stevenson). Abbreviations: ANOVA, analysis of variance; AFR, animal facility rearing; CC, corpus callosum; FG-7142, $N$-methyl- $\beta$-carboline-3-carboxamide; $\mathrm{H}$, handling; HPA, hypothalamic-pituitary-adrenal; LFP, local field potential; mPFC, medial prefrontal cortex; MS, maternal separation.
The early rearing environment plays a critical role in mediating stress reactivity later in life (Macri and Würbel, 2006). Separating rat pups from their mothers repeatedly during the postnatal period has different effects on responsivity to stressors in adulthood depending on the duration of separation. Pups subjected to brief separations in early life, known as handling $(\mathrm{H})$, show reduced behavioral measures of fear and attenuated neuroendocrine activation in response to stressors, compared to rats left undisturbed as pups (see Meaney et al., 1996 for review). In contrast, pups repeatedly subjected to prolonged maternal separation (MS) during this period display increased anxiety, compared to those subjected to $\mathrm{H}$ (Caldji et al., 2000; Huot et al., 2001; Francis et al., 2002). MS also enhances hypothalamic corticotropin releasing factor expression and potentiates the release of adrenocorticotropin and corticosterone in response to stressors, compared to $\mathrm{H}$ (Huot et al., 2001; Francis et al., 2002; Plotsky et al., 2005).

The medial prefrontal cortex (mPFC) plays an important role in modulating various stress responses. This region is involved in mediating behavioral coping responses to stressors (Amat et al., 2005, 2006). Activation of glucocorticoid receptors within mPFC also regulates the neuroendocrine stress response by modulating negative feedback of the hypothalamic-pituitary-adrenal (HPA) axis (Radley et al., 2006). Various neurotransmitters in mPFC have been implicated in mediating these behavioral and neuroendocrine responses to stressors, including GABA (Martijena et al., 2002; Tan et al., 2004) and dopamine (Bland et al., 2003). Importantly, activation of MPFC and its dopamine innervation have been shown to occur asymmetrically in response to stressors, suggesting a role for lateralized mPFC and mesocortical dopamine function in mediating adaptive coping responses to stress (Sullivan, 2004).

Early postnatal life is a critical period for the development of mPFC (Benes et al., 2000). Maturation of mPFC GABA neurons and mesocortical dopamine projections occurs during this period (Vincent et al., 1995; Benes et al., 1996). The early rearing environment exerts plasticity on the developing $\mathrm{mPFC}$ which likely affects its function later in life. Dendritic morphology in MPFC is altered by maternal deprivation and $\mathrm{H}$, compared to animals left undisturbed in early life (Helmeke et al., 2001a,b). Compared to $H$, MS reduces the expression of glucocorticoid receptors in mPFC (Ladd et al., 2004), suggesting a possible mechanism by which negative feedback of HPA axis function is impaired in these animals. Furthermore, MS may alter dopamine and GABA transmission in mPFC (Matthews et al., 2001; Helmeke et al., 2008). Compared to undisturbed controls, basal mPFC do-

0306-4522/08\$32.00+0.00 @ 2008 IBRO. Published by Elsevier Ltd. All rights reserved.

doi:10.1016/j.neuroscience.2008.06.013 
pamine levels are increased and stress-induced dopamine release in $\mathrm{mPFC}$ is attenuated with maternal deprivation (Jezierski et al., 2007). MS decreases $\mathrm{GABA}_{\mathrm{A}}$ and benzodiazepine receptor expression in mPFC, compared to $\mathrm{H}$, suggesting changes in $\mathrm{GABA}_{\mathrm{A}}$ receptor signaling (Caldji et al., 2000). Alterations in mPFC function may therefore contribute to differences in stress responsivity mediated by the early environment.

We have recently demonstrated reduced neuronal activity in MPFC with MS in response to systemic administration of the benzodiazepine receptor partial inverse agonist $N$-methyl$\beta$-carboline-3-carboxamide (FG-7142), suggesting altered mPFC GABA transmission with MS (Stevenson et al., 2008). This drug causes anxiety, impairs working memory and induces corticosterone release (Pellow and File, 1985, 1986; Murphy et al., 1996). FG-7142 also activates mPFC (Singewald et al., 2003; Stevenson et al., 2007, 2008) and dopamine transmission in this region (Murphy et al., 1996; Dazzi et al., 2001). Given that FG-7142 mimics various effects of stressors, our previous findings may also model an impairment of stress-induced mPFC function with MS. However, the extent to which the early rearing environment is involved in mediating lateralized mPFC function in response to stressors remains unclear. Furthermore, the early environment may mediate alterations in cortical hemispheric connectivity (Denenberg et al., 1981) relevant to modulating stress reactivity. Thus, the present study was conducted to examine the potential role of early rearing conditions in mediating lateralized activation and hemispheric functional coupling of $\mathrm{mPFC}$. In vivo electrophysiology, under isoflurane anesthesia, was used to conduct acute neuronal activity recordings in left and right mPFC in response to FG-7142 in adult rats previously subjected to $M S, H$ or animal facility rearing (AFR) as pups.

\section{EXPERIMENTAL PROCEDURES}

\section{Animals}

All experiments were performed in Lister hooded rats. Animals were housed on a 12-h light/dark cycle (lights on at 7 AM) with free access to food and water. All experimental procedures were carried out with approval from the University of Nottingham ethics committee and in accordance with the Animals (Scientific Procedures) Act 1986, UK (Project License number 40/2715). Every effort was made to minimize both the number of animals used and the animals' suffering in the experiments described below.

\section{MS procedure}

Adult females (Charles River, UK) were bred with in-house colony males (Biomedical Services Unit, University of Nottingham Medical School). After breeding, females were group housed (three to four/cage) for approximately 2 weeks. Pregnant females were then singly housed for approximately 1 week prior to parturition. On the day of birth (postnatal day 0 ), dams and pups were left undisturbed. The day after birth (postnatal day 1), litters were culled to five male and five female pups where possible. MS consisted in separating pups from their respective dams for 6 $\mathrm{h} /$ day on postnatal days 2-14. Dams were removed from their home cages and placed in adjacent cages with free access to food and water throughout the duration of separation. Pups were then removed and placed, as a litter, in an incubator in the same room and maintained at a constant temperature $\left(30-32{ }^{\circ} \mathrm{C}\right)$ throughout the duration of separation. Separations were conducted during the light cycle. Although several previous studies have used shorter separation durations (up to $3 \mathrm{~h}$; Caldji et al., 2000; Huot et al., 2001; Francis et al., 2002), rat dams in the wild are known to forage away from their pups for up to $3 \mathrm{~h}$ at a time (Calhoun, 1962). Thus a longer duration of MS was deliberately chosen as it would presumably be more stressful for both dams and pups. Previous studies also indicate that $6 \mathrm{~h}$ of MS induces alterations in offspring behavior (Matthews et al., 1996, 1999; Gustafsson and Nylander, 2006), neurochemistry (Matthews et al., 2001; Gartside et al., 2003) and neuronal activity (Stevenson et al., 2008). Pups subjected to $\mathrm{H}$ were also used and underwent the same separation procedure except for a much briefer duration (15 min/day on postnatal days 2-14). Pups not separated from their dams but subjected to standard AFR practices (e.g. regular cage cleaning) served as controls. Pups were weaned on postnatal day 23 and housed two to four/cage by sex and early rearing group. Adult (60-90 days) male offspring of each early rearing group from at least two different litters were used in the experiments described below.

\section{Surgery}

All drugs and chemicals were obtained from Sigma (MO, USA) unless otherwise stated. Anesthesia was induced with $3.5 \%$ isoflurane (IVAX Pharmaceuticals, UK) in a $50 \% \mathrm{~N}_{2} \mathrm{O}: 50 \% \mathrm{O}_{2}$ mixture. The isoflurane level was reduced progressively and maintained at $2.0 \%$ throughout surgery to ensure complete inhibition of the hind-paw withdrawal reflex. Body temperature was monitored and maintained at $\sim 37{ }^{\circ} \mathrm{C}$ using a homeothermic heating pad. The femoral vein was cannulated with Portex fine bore polythene tubing $(0.28 \mathrm{~mm}$ ID) for i.v. administration of drug (see below) prior to placing the animal in a stereotaxic frame. The incisor bar was adjusted to maintain the skull horizontal and a scalp incision was made. A small portion of the skull $\left(\sim 2 \mathrm{~mm}^{2}\right)$ was removed prior to excision of the dura mater over the left and right mPFC. Two eight-microwire electrode arrays (NB Laboratories, TX, USA), configured as bundles, were used to record unit activity from multiple neurons and local field potential (LFP) activity simultaneously in the left and right mPFC. Electrode arrays were lowered into the left and right infralimbic cortices $(3.2 \mathrm{~mm}$ anterior and $0.5-0.7 \mathrm{~mm}$ lateral to bregma; $4.3-$ $4.5 \mathrm{~mm}$ ventral to the cortical surface) using the atlas coordinates of Paxinos and Watson (1997).

\section{Recording procedure}

Microwire electrodes (Teflon-coated stainless steel, $50 \mu \mathrm{m}$ diameter/ wire, NB Laboratories) had an impedance of $\sim 100 \mathrm{k} \Omega$ measured at $1 \mathrm{kHz}$ (Robinson, 1968). Electrode arrays were connected via a unity-gain multi-channel headstage (HST/8m-G1, Plexon Inc., TX, USA) to a multi-channel preamplifier. Extracellular action potential spikes and LFPs (gain 1000×; band-pass filtered at $250 \mathrm{~Hz}-8 \mathrm{kHz}$ (spikes) and $0.7-170 \mathrm{~Hz}$ (LFPs); Plexon Inc.) were fed to a Multichannel Acquisition Processor system (Plexon Inc.) linked to a host PC (Dell $1.5 \mathrm{GHz}$; Windows 2000), providing simultaneous $40 \mathrm{kHz}$ $(25 \mu \mathrm{s}) \mathrm{A} / \mathrm{D}$ conversion on each channel at 12 bit resolution. The system provided further additional programmable amplification and filtering of spikes (final gain up to $32,000 \times$, final bandwidth $400 \mathrm{~Hz}-5$ $\mathrm{kHz})$. Unit activity was displayed on D11 5000 series dual-beam (Tektronix, OR, USA) and 507 analog-digital (Hameg Instruments, Germany) oscilloscopes and also monitored aurally with the aid of a loudspeaker. LFP signals were monitored from one microwire in each array and were digitized at $1 \mathrm{kHz}$.

\section{Drug administration}

Electrode arrays were allowed to settle for $\sim 30$ min after being lowered into MPFC and BLA prior to recording basal activity for 20-30 min in each region. Following basal recordings, animals 
received repeated systemic (i.v.) injections of FG-7142. Animals were injected with vehicle $(10 \%$ Cremophor EL in $0.5 \mathrm{~mL} / \mathrm{kg}$; Hart et al., 1998) and three doses of FG-7142 $(0.1,1.0$ and $10.0 \mathrm{mg} / \mathrm{kg}$ in $0.5 \mathrm{~mL} / \mathrm{kg}$ ) every $5 \mathrm{~min}$. Each dose was followed immediately by injection of heparinized saline (50 $\mu \mathrm{L}$; CP Pharmaceuticals Ltd., UK) to flush the cannula and thus ensure that drug was administered completely. Drug and saline administration, combined, occurred over $30 \mathrm{~s}$. Given the relatively short half-life $(\sim 30 \mathrm{~min})$ of FG-7142 (Dorow et al., 1983; Yuan and Manabe, 1996), this dosing regimen was used to ensure that the effect of a particular dose did not subside prior to administration of the subsequent dose.

\section{Histology}

The total duration of each experiment was approximately $4-5 \mathrm{~h}$. At the end of each experiment, current $(0.1 \mathrm{~mA})$ was passed through microwires in each electrode array for 5-7 $s$ to deposit ferric ions at the electrode tips. Transcardial perfusion with $0.9 \%$ saline, followed by a $4 \%$ paraformaldehyde $/ 4 \%$ potassium ferrocyanide solution, was conducted under deep anesthesia, allowing for the marking of recording sites using the Prussian Blue reaction (Green, 1958). Brains were removed and stored in perfusion medium until sliced. Brains were sectioned $(200 \mu \mathrm{m})$ with a vibratome to determine electrode array placements within left and right $\mathrm{mPFC}$

\section{Data analysis}

Spike sorting. Spike discrimination was achieved with OffLine Sorter software (Plexon Inc.) using both automatic and manual sorting. Principal component analysis was used to display the waveforms recorded from each electrode in two-dimensional space. Each electrode was checked for artifacts (e.g. noise) which were removed manually. Automatic sorting (valley-seeking) methods were then used to separate the waveforms into individual units. The resulting clusters were inspected and the units were considered to be separate only if the cluster borders did not overlap. Furthermore, waveforms which were not consistent with the shape of action potentials and occurred within the absolute refractory period (1.1 ms; Homayoun et al., 2005) were also manually removed. Finally, clusters were considered to be single units only if the autocorrelogram showed that no significant errors occurred in sorting as a result of noise. Although the majority of electrodes showed only one discriminated unit, up to three units were observed on some electrodes.

Neuronal subtypes in MPFC have previously been characterized based on differences in firing rate and action potential waveform characteristics. Studies have shown that regular-spiking neurons, presumed to be glutamatergic pyramidal cells, have a firing rate $<10 \mathrm{~Hz}$; fast-spiking neurons, presumed to be local GABA interneurons, fire at a rate $>10 \mathrm{~Hz}$ (Jung et al., 1998; Homayoun et al., 2005; Laviolette et al., 2005). None of the neurons recorded from $\mathrm{mPFC}$ had firing rates $>10 \mathrm{~Hz}$ and were all therefore initially presumed to be pyramidal cells. Evidence also indicates that the majority of putative pyramidal mPFC neurons have a biphasic waveform, with an initial negative deflection followed by a positive deflection in their action potential waveform. The remaining neurons show triphasic waveforms, with a small positive deflection preceding the initial negative deflection, and are presumed to be interneurons (Sesack and Bunney, 1989; Gronier and Rasmussen, 2003). Examination of the average waveform shape of the mPFC units recorded in the present study revealed that 182 of the 187 recorded mPFC units exhibited waveform characteristics consistent with pyramidal cells. The five units which were putatively characterized as interneurons were omitted from the data analysis. A paucity of recordings from interneurons in MPFC has been observed in other studies (Homayoun et al., 2005; Laviolette et al., 2005; Stevenson et al., 2007, 2008) and is likely due to both anatomical and technical considerations. Anatomical studies indi- cate that the majority of neurons in MPFC are pyramidal cells (Gabbott et al., 1997). Furthermore, the large diameter $(50 \mu \mathrm{m})$ metal electrodes used in the present study preferentially detect activity in larger pyramidal cells compared to smaller interneurons (Snodderly, 1973).

Unit activity. Electrophysiological data were analyzed using NeuroExplorer (NEX Technologies, TX, USA). Basal firing rate was defined as the mean $( \pm$ S.E.M. $)$ firing rate $(\mathrm{Hz})$ during the final $300 \mathrm{~s}$ of the baseline recording period (i.e. immediately preceding vehicle infusion). The effects of the different early rearing environments on the mean firing rate of mPFC units under basal conditions were analyzed separately in the left and right hemispheres using a one-way analysis of variance (ANOVA), with early rearing group as the between-subject factor. As previously reported, systemic (i.v.) administration of FG-7142 had immediate and sustained effects on unit activity (Stevenson et al., 2007, 2008). Thus the mean ( \pm S.E.M.) firing rate was determined for the $300 \mathrm{~s}$ period immediately following vehicle or drug injection. The effects of the different early rearing environments on FG-7142-induced changes in the mean firing rate of mPFC units were analyzed separately in the left and right hemispheres using a two-way ANOVA, with early rearing group as the between-subject factor and FG-7142 dose as the within-subject factor. When indicated, post hoc comparisons were performed using Tukey's Honestly Significant Difference (HSD) test. The level of significance was set at $P<0.05$.

LFP activity. The LFP is thought to represent the vector sum of all (i.e. dendritic, somatic, axonal, synaptic) electrical activity in a relatively large volume (up to $1 \mathrm{~mm}^{3}$ ) of a given brain region and is therefore attributable to both pre- and post-synaptic activity of a neuronal population (Bullock, 1997). Power spectra of LFP activity were generated using periodogram-based spectral estimation techniques (Halliday et al., 1995). LFP power spectra from left and right mPFC were generated for individual animals from the $300 \mathrm{~s}$ epochs associated with basal activity and each dose of FG-7142. Individual power spectra from animals in each early rearing group were then combined to give pooled power spectral estimates of LFP activity in left and right mPFC across the population of animals in each group (Amjad et al., 1997). Comparisons of LFP power between the early rearing groups in left or right $\mathrm{mPFC}$ were assessed under basal conditions and separately in response to each dose of FG-7142. Differences between early rearing groups were initially quantified using a $\chi^{2}$ extended difference test. This test is based on the hypothesis of equal LFP power across the groups, with significant values of $\chi^{2}$ indicating that this null hypothesis does not provide a plausible interpretation of the data. The $\chi^{2}$ extended difference test is applied separately at each frequency of interest. Significance is assessed through inclusion of an upper $95 \%$ confidence limit, based on the null hypothesis (Amjad et al., 1997; Farmer et al., 2007). At frequencies where $\chi^{2}$ exceeded the confidence limit, differences in LFP power between early rearing groups were further quantified using a log ratio comparison of spectra test (Diggle, 1990). Confidence intervals $(95 \%)$ for these ratios were then used to characterize any statistically significant differences in LFP power between groups.

LFP synchronization. Early rearing group differences in functional coupling between left and right MPFC were determined by assessing LFP coherence under basal conditions and in response to FG-7142. Coherence is a measure of linear association between two signals in the frequency domain (Halliday et al., 1995). This measure is dimensionless and is bounded from 0 to 1 , with a value of zero indicating no linear relationship and a value of one indicating two identical signals at a particular frequency. Coherence spectra were calculated from the periodogram-based spectral estimates described above and generated for individual animals from the $300 \mathrm{~s}$ epochs associated with basal activity and 
A

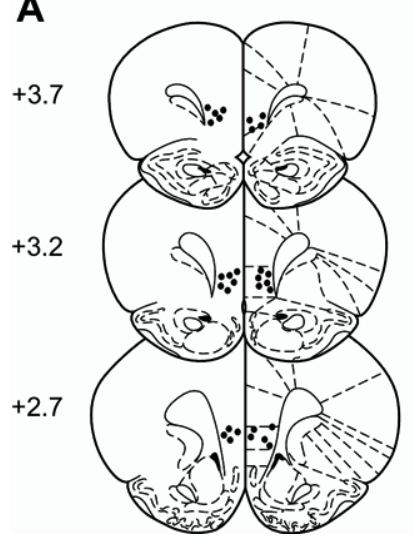

B

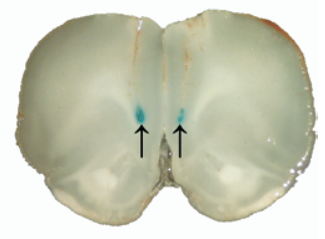

Fig. 1. (A) Schematic representation of multi-electrode array placements within left and right mPFC. The distance $(\mathrm{mm})$ anterior to bregma is indicated beside each coronal section (Paxinos and Watson, 1997). (B) Photomicrograph of array placements within left and right mPFC. Arrows show the ventral extent of the Prussian Blue reaction, indicating the placement of the arrays.

each dose of FG-7142. Coherence from individual animals in each early rearing group was then combined to give pooled coherence estimates of LFP synchronization between left and right mPFC across the population of animals in each group (Amjad et al.,

A
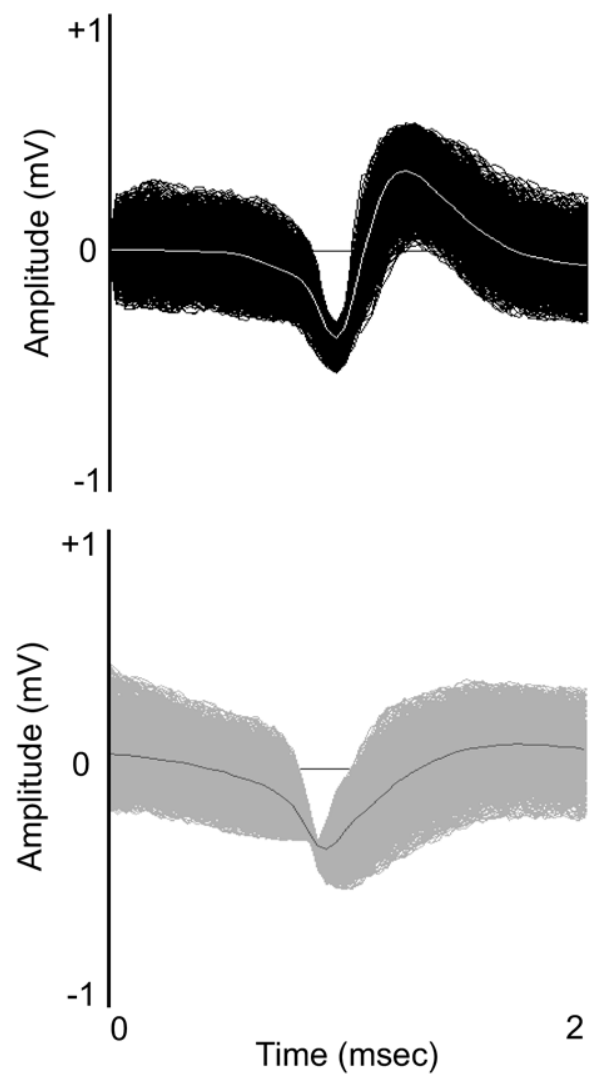

PC2

1997). Comparison of pooled coherence spectra between early rearing groups was assessed under basal conditions and separately for each dose of FG-7142. As with LFP power, differences in coherence between early rearing groups were initially quantified using the $\chi^{2}$ extended difference test applied separately at each frequency of interest. At frequencies where $\chi^{2}$ exceeded the confidence limit, differences in LFP coherence between early rearing groups were further quantified using a comparison of coherence test (Rosenberg et al., 1989). Confidence intervals (95\%) for these comparisons were used to examine any statistically significant differences in LFP coherence between groups.

\section{RESULTS}

The locations of multi-electrode array recording sites within left and right $\mathrm{mPFC}$ are shown in Fig. 1. Only animals with histologically-confirmed placements in left and right mPFC (ventral prelimbic/infralimbic cortices) were included in the data analysis ( $n=5$ rats/group). Similarly, only activity recorded from mPFC neurons ( $n=23-38$ units/hemisphere/ group) putatively classified as glutamatergic pyramidal cells was included in the data analysis (see above). An example of discriminated unit activity recorded from two putative glutamatergic pyramidal neurons is illustrated in Fig. 2.

Multiple unit and LFP activity in left and right mPFC under basal conditions from one experiment is represented

B

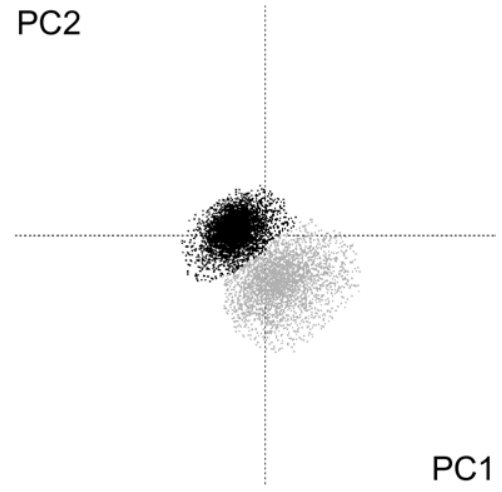

Fig. 2. An example of discriminated unit activity from two putative glutamatergic neurons recorded from one microwire of a multi-electrode array. (A) Cumulative waveforms (black and gray) and the resulting average waveforms (white and black) of unit activity recorded from two neurons.

(B) Cluster analysis of unit activity from two neurons (black and gray) in two-dimensional space using principal component analysis. 


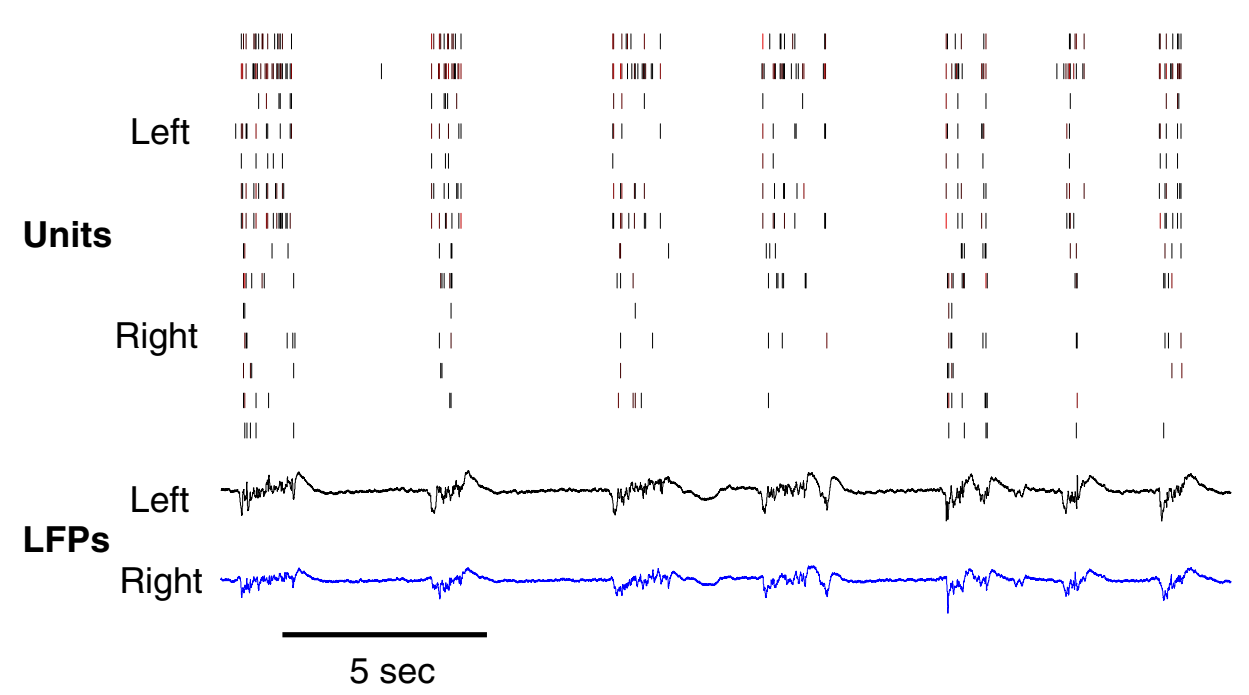

Fig. 3. Representative unit rasters and LFP plots recorded under basal conditions in one experiment. The first seven raster plots correspond to left $\mathrm{mPFC}$ units and the last seven plots represent units in right mPFC. Unit activity in both hemispheres was characterized by irregular burst firing. Similarly, LFPs in left and right mPFC displayed synchronized activity characterized by irregular deflections in potential corresponding to unit firing.

in Fig. 3. Neurons in both hemispheres exhibited an irregular firing pattern characterized by periods of low tonic activity coupled with phasic burst firing, in animals from each early rearing group. This pattern of neuronal activity has been reported previously in mPFC (Gronier and Rasmussen, 2003; Jackson et al., 2004; Homayoun et al., 2005; Stevenson et al., 2007). The LFP activity pattern mirrored that of neuronal firing in both hemispheres such that the initial negative deflection in potential coincided with neuronal activity in left and right mPFC. This temporal association between unit and LFP activity has also been previously observed in cortical regions (Steriade, 1997), including mPFC (Stevenson et al., 2007).

\section{Role of early environment on basal mPFC activity}

Basal unit activity in left and right mPFC in each of the early rearing groups is shown in Fig. 4. A one-way ANOVA showed no significant differences in mean firing rate between early rearing groups in left $\operatorname{mPFC}\left(F_{(2,96)}=0.07 ; P=\right.$ $0.93)$. Conversely, a one-way ANOVA revealed a significant main effect of early rearing group on mean firing rate in right $\mathrm{mPFC}\left(F_{(2,85)}=3.68 ; P<0.05\right)$. Moreover, post hoc analysis showed that MS significantly decreased mean firing rate, compared to AFR and $\mathrm{H}(P<0.05)$, indicating

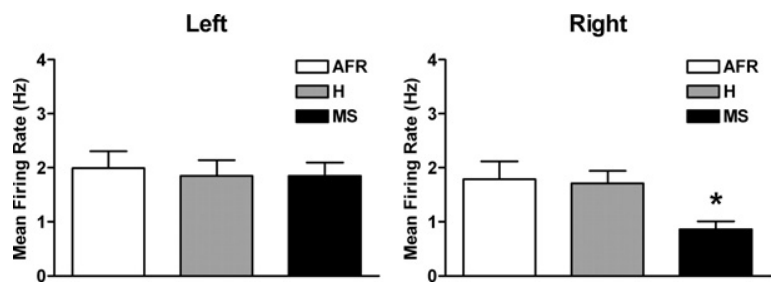

Fig. 4. Effects of early rearing environment on basal unit firing rate in left and right mPFC. There were no differences between early rearing groups in left $\mathrm{mPFC}$. However, MS reduced unit activity in right $\mathrm{mPFC}$, compared to $\mathrm{H}$ and $\operatorname{AFR}\left({ }^{*} P<0.05\right)$. that MS induced a reduction in basal MPFC unit activity which was lateralized to the right hemisphere.

Fig. 5 shows LFP power in left and right mPFC under basal conditions in the different early rearing groups. In left $\mathrm{mPFC}$, the $\chi^{2}$ extended difference test revealed significant differences in power between early rearing groups over the entire frequency range examined $(0-30 \mathrm{~Hz})$, showing robust differences at lower $(<12 \mathrm{~Hz})$ frequencies and modest differences at higher $(>12 \mathrm{~Hz})$ frequencies $(P<0.05)$. Further pairwise comparisons using log ratio tests showed significantly enhanced power at predominantly lower frequencies $(<10 \mathrm{~Hz})$ with $\mathrm{AFR}$, compared to $\mathrm{H}$ and $\mathrm{MS}$ $(P<0.05)$. Slight increases in power were also observed with MS, compared to $\mathrm{H}(P<0.05)$. In right mPFC, the $\chi^{2}$ extended difference test also revealed highly significant differences between early rearing groups over the entire frequency range $(P<0.05)$. In contrast to left mPFC, log ratio tests showed significantly greater power at all frequencies with $\mathrm{H}$, compared to $\mathrm{AFR}$ and $\mathrm{MS}(P<0.05)$. Modest differences between the AFR and MS groups were also apparent at various frequencies $(P<0.05)$. Therefore differences in basal LFP power were observed in each mPFC hemisphere which depended on the early rearing conditions.

Basal LFP coherence between left and right $\mathrm{mPFC}$ is also shown in Fig. 5. The $\chi^{2}$ extended difference test revealed significant differences in left-right coherence between early rearing groups at various lower $(<4 \mathrm{~Hz})$, intermediate $(8-16 \mathrm{~Hz})$ and higher $(22-28 \mathrm{~Hz})$ frequency ranges $(P<0.05)$. Pairwise comparison of coherence tests applied within these frequency ranges showed significantly augmented coherence with $\mathrm{H}$, compared to MS, at lower frequencies. Modest differences between the AFR and $\mathrm{H}$ groups were also observed within these frequency ranges $(P<0.05)$, as were differences between the AFR and MS groups $(P<0.05)$. Thus hemispheric synchronization in 
A

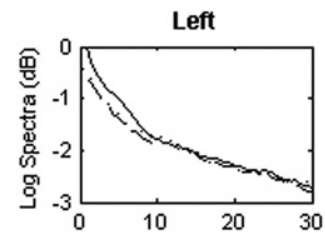

B

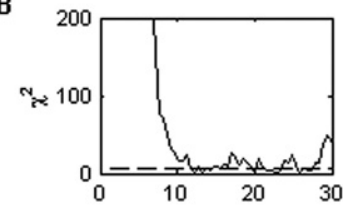

C
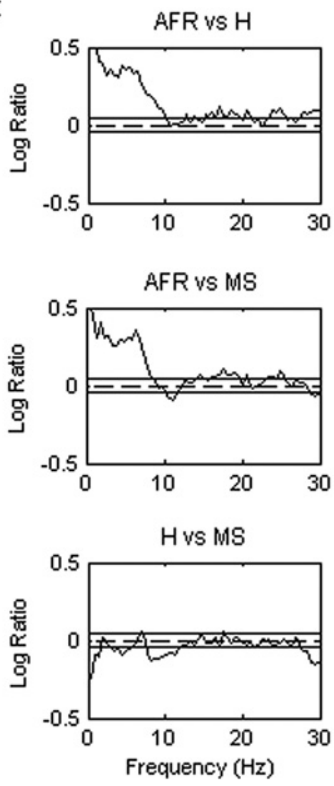
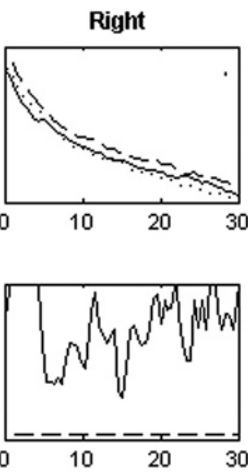

AFR vs $\mathrm{H}$

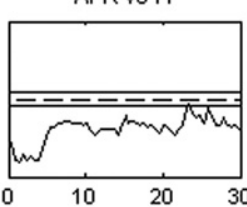

AFR vs MS

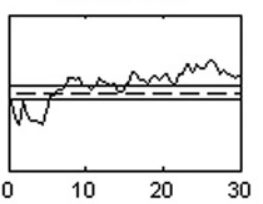

Hvs MS

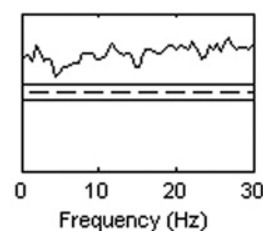

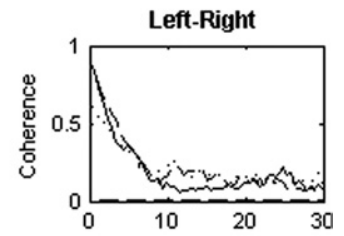

E

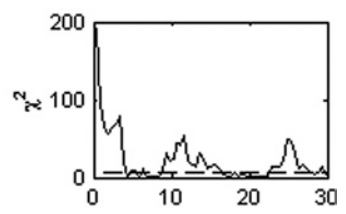

F
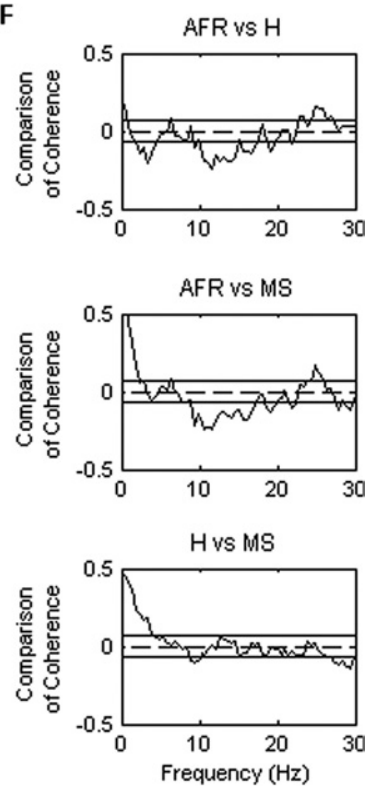

Fig. 5. Effects of early rearing environment on basal LFP power in left and right mPFC and LFP coherence between left and right mPFC. (A) Log spectral estimates of LFP power with different early rearing conditions (AFR: solid lines; $\mathrm{H}$ : dashed lines; MS: dotted lines). (B) Significant differences in power were observed at various frequencies between the early rearing groups in both hemispheres $(P<0.05)$ as revealed by $\chi^{2}$ extended difference tests, where the horizontal dashed lines at the bottom of the plots indicate the $95 \%$ confidence limit. (C) Log ratio plots for comparing power spectra. The two solid horizontal lines indicate the upper and lower 95\% confidence limits. In left mPFC, pairwise comparisons showed increased power with AFR, compared to $\mathrm{H}$ and MS $(P<0.05)$. In contrast, increased power was observed with $\mathrm{H}$, compared to AFR and MS $(P<0.05)$, in right mPFC. (D) LFP coherence estimates for the AFR (solid), H (dashed) and MS (dotted) groups. (E) Significant differences in coherence between early rearing groups were observed $(P<0.05)$. $(F)$ Comparison of coherence plots, where the two solid horizontal lines represent the upper and lower $95 \%$ confidence limits. Pairwise comparisons showed predominantly increased coherence with $\mathrm{H}$, compared to AFR and MS $(P<0.05)$.

mPFC was altered by the early rearing environment under basal conditions.

\section{FG-7142 induces hemisphere-dependent mPFC activation: Role of early environment}

Changes in unit activity in response to FG-7142 in left and right $\mathrm{mPFC}$ in each of the early rearing groups are shown in Fig. 6. In left mPFC, a two-way ANOVA revealed significant main effects of early rearing group $\left(F_{(2,96)}=3.96 ; P<\right.$ $0.05)$ and FG-7142 dose $\left(F_{(3,96)}=17.72 ; P<0.0001\right)$, as well as a significant group $\times$ dose interaction $\left(F_{(6,288)}=\right.$ 13.64; $P<0.0001)$. Post hoc analysis indicated significantly increased mean firing rates with AFR (Vehicle vs. 1.0 and $10.0 \mathrm{mg} / \mathrm{kg} ; P<0.0001$ ) and MS (Vehicle vs. 0.1 and $1.0 \mathrm{mg} / \mathrm{kg} ; P<0.01$ ) elicited by FG-7142; however, no such effect occurred with $\mathrm{H}(P=0.29)$. Furthermore, FG-7142 induced significantly greater unit firing with AFR, compared to $M S$ (1.0 mg/kg: $P<0.01 ; 10.0 \mathrm{mg} / \mathrm{kg}: P<0.0001)$. In right mPFC, a two-way ANOVA also revealed significant main effects of early rearing group $\left(F_{(2,85)}=6.47 ; P<0.01\right)$ and FG-7142 dose $\left(F_{(3,85)}=8.93 ; P<0.0001\right)$, as well as a significant group $\times$ dose interaction $\left(F_{(6,255)}=5.71\right.$; $P<0.0001)$. In contrast to left mPFC, post hoc analysis indicated that FG-7142 significantly increased mean firing rate only with $\mathrm{H}$ (Vehicle vs. $0.1,1.0$ and $10.0 \mathrm{mg} / \mathrm{kg}$; $P<0.0001)$, but not AFR $(P=0.82)$ or MS $(P=0.66)$, in right mPFC. Therefore FG-7142-induced unit activity in mPFC occurred in a hemisphere-dependent manner with different early rearing conditions.

FG-7142-induced alterations in LFP power in left and right $\mathrm{mPFC}$ in the different early rearing groups are shown in Fig. 7. In left mPFC, $\chi^{2}$ extended difference tests re- 

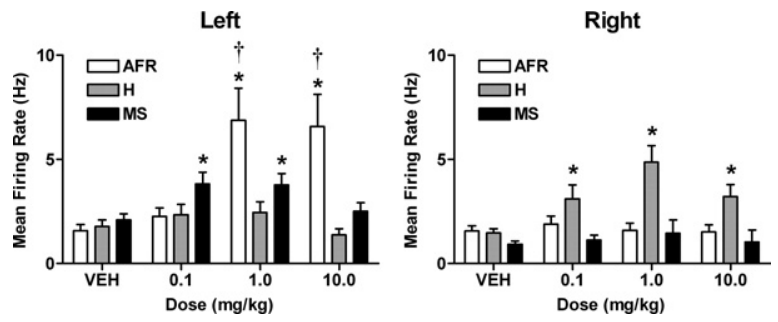

Fig. 6. Effects of early rearing environment on unit firing rate in left and right mPFC elicited by FG-7142. In left mPFC, FG-7142 increased unit firing rate with MS and AFR ( ${ }^{*}$ FG-7142 vs. vehicle; $P<0.01$ ), but not $\mathrm{H}$. Moreover, this increase was greater with AFR, compared to MS $\left({ }^{\dagger} P<0.01\right)$. However, in right mPFC, FG-7142 increased unit firing rate with $\mathrm{H}$ ( ${ }^{*} \mathrm{FG}-7142$ vs. vehicle; $P<0.0001$ ), but not AFR or MS.

vealed significant differences in power between early rearing groups at each dose of FG-7142, over the majority of the frequency range examined $(P<0.05)$. In general, pairwise log ratio tests demonstrated the following significant differences between early rearing groups: $A F R>M S>H$ $(P<0.05)$. These differences in power were apparent at all FG-7142 doses over most frequencies. In right mPFC, $\chi^{2}$ extended difference tests also revealed significant differences between early rearing groups at each dose of FG7142 , again over most of the frequency range $(P<0.05)$. Compared to left mPFC, pairwise log ratio tests showed more complex differences in power between early rearing groups which depended on FG-7142 dose and the frequencies examined. At the lower $(0.1 \mathrm{and} 1 \mathrm{mg} / \mathrm{kg}$ ) doses of FG-7142, the following significant differences between early rearing groups were generally observed at most frequencies: $\mathrm{H}>\mathrm{MS}>\mathrm{AFR}(P<0.05)$. Frequency-dependent differences in power were also apparent between early rearing groups at the highest $(10 \mathrm{mg} / \mathrm{kg})$ dose of FG-7142 $(P<0.05)$. These differences in LFP power between early rearing groups in response to FG-7142 were broadly similar to those observed for unit activity in left and, to a lesser extent, right mPFC. Thus, as with unit activity, altered LFP power in MPFC induced by FG-7142 occurred in a hemisphere-dependent manner with different early rearing conditions.

Fig. 8 shows FG-7142-induced changes in LFP coherence between left and right MPFC in the different early rearing groups. Qualitative inspection of the data indicated that FG-7142 enhanced left-right LFP coherence in a dose-related manner. Significant differences between early rearing groups were also revealed with $\chi^{2}$ extended difference tests $(P<0.05)$, indicating that progressively greater differences were observed between the groups over a wider range of frequencies with escalating doses of FG-7142. Pairwise comparison of coherence tests showed
A

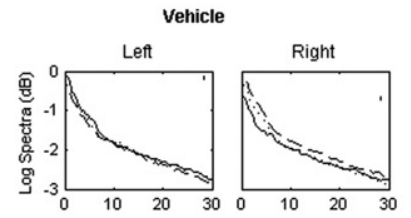

B

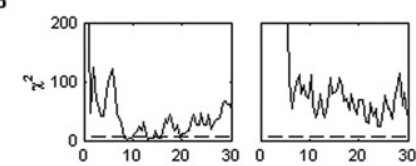

C
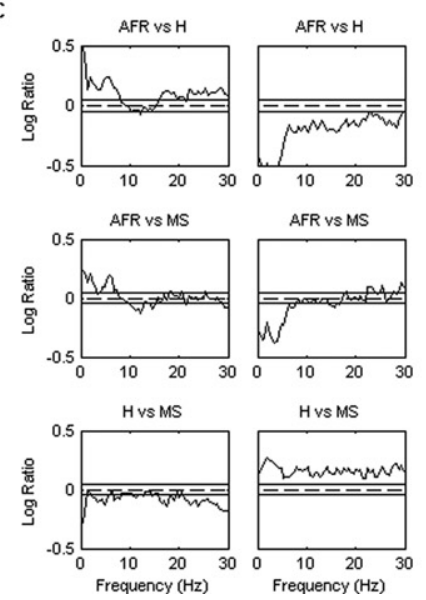
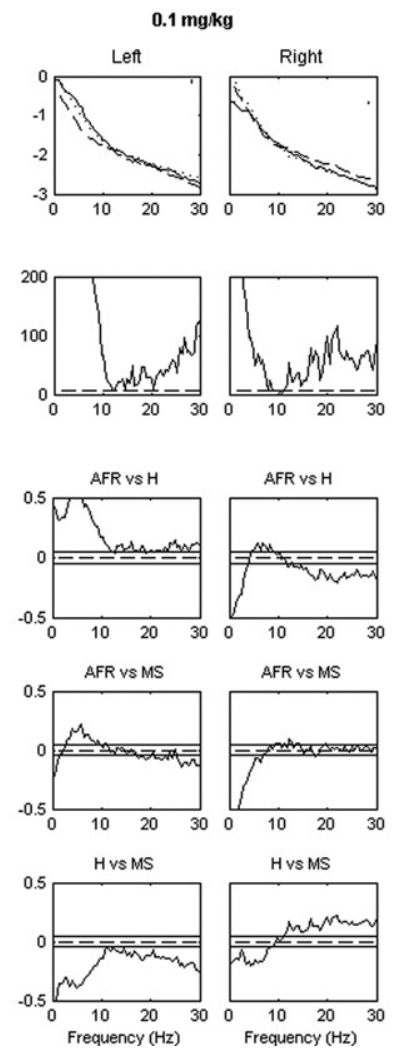
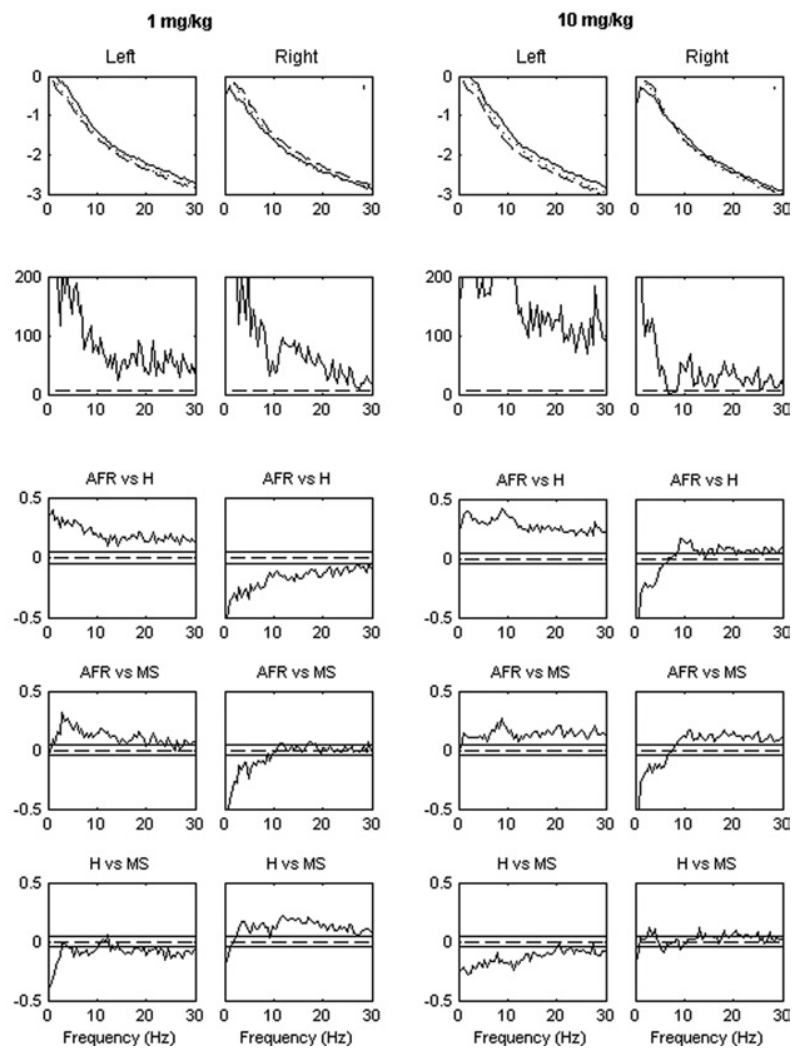

H vs MS

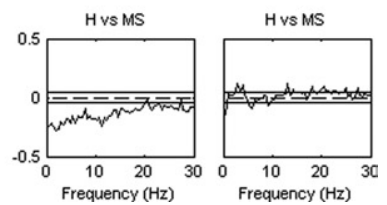

Fig. 7. Effects of early rearing environment on LFP power in left and right mPFC in response to FG-7142. (A) Power spectral estimates for the AFR (solid), H (dashed) and MS (dotted) groups in response to different doses of FG-7142. (B) Significant differences in power between early rearing groups elicited by FG-7142 were observed at various frequencies in both hemispheres $(P<0.05)$. (C) In left mPFC, pairwise comparisons showed the following differences in power with each dose of FG-7142: AFR $>M S>H(P<0.05)$. In right mPFC, the following differences in power were generally observed at the lower $(0.1$ and $1 \mathrm{mg} / \mathrm{kg})$ doses of FG-7142: $\mathrm{H}>\mathrm{MS}>\mathrm{AFR}(P<0.05)$. 
A
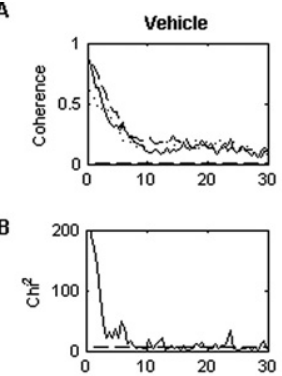

C
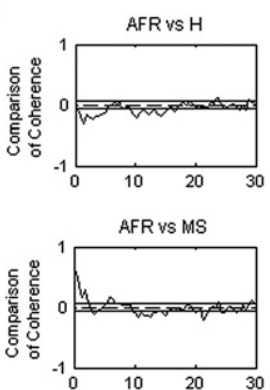

Hvs MS

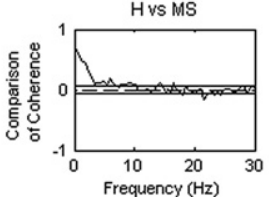

$0.1 \mathrm{mg} / \mathrm{kg}$
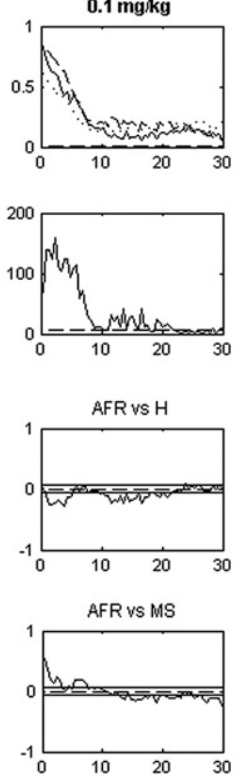

Hvs MS

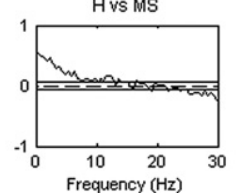

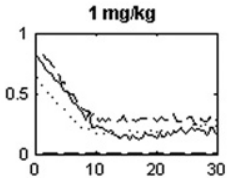
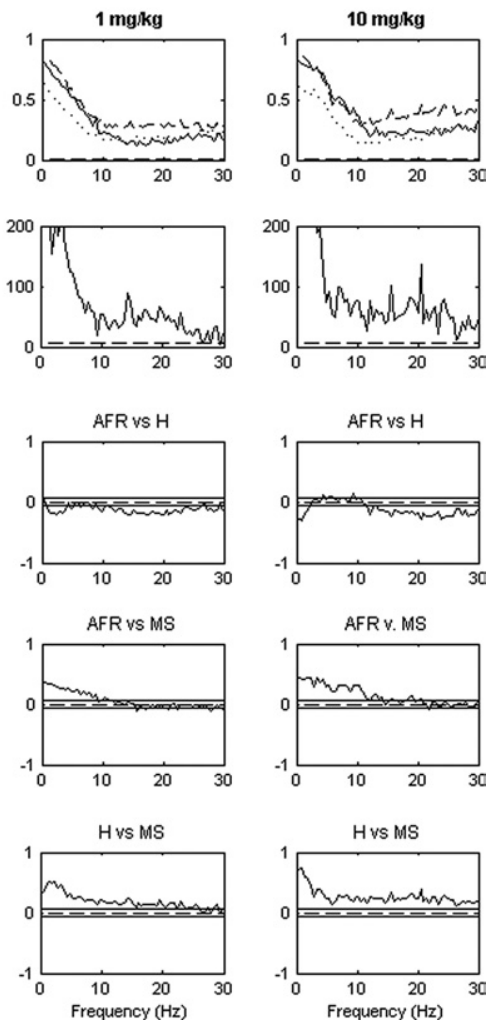

Fig. 8. Effects of early rearing environment on LFP coherence between left and right mPFC induced by FG-7142. (A) Coherence estimates for the AFR (solid), H (dashed) and MS (dotted) groups in response to FG-7142. (B) Significant differences between early rearing groups were observed which became more pronounced with increasing doses of FG-7142 $(P<0.05)$. (C) Pairwise comparisons showed the following differences in coherence between early rearing groups: H>AFR $>$ MS $(P<0.05)$; these differences were also more apparent with increasing doses of FG-7142.

the following significant differences between early rearing groups: $\mathrm{H}>\mathrm{AFR}>\mathrm{MS}(P<0.05)$. Again, these differences in coherence became more pronounced with increasing doses of FG-7142. Therefore, altered hemispheric synchronization in mPFC was observed with different early rearing conditions in response to FG-7142.

\section{DISCUSSION}

The present results confirm that the early environment mediates hemispheric lateralization and synchronization of mPFC function in adulthood. Basal unit activity was decreased with MS selectively in right MPFC. Basal LFP activity was reduced by MS in left MPFC, compared to $\mathrm{AFR}$, and right mPFC, compared to $\mathrm{H}$. Hemispheric synchronization of basal LFP activity was also attenuated by MS at lower frequencies. FG-7142 induced lateralized effects on mPFC activity with different early rearing conditions. Unit activity in left mPFC was elicited selectively with AFR and MS, an effect which occurred to a lesser extent with MS compared to AFR. LFP activity was also greater in left $\mathrm{mPFC}$ with AFR and MS, with attenuated activity again observed with MS compared to AFR. In contrast, unit activity in right mPFC was increased selectively with $\mathrm{H}$. Similarly, LFP activity was predominantly greater with $\mathrm{H}$ in right $\mathrm{mPFC}$. Finally, MS reduced and $\mathrm{H}$ enhanced leftright coupling of mPFC LFP activity with FG-7142 treatment in a dose-dependent manner.
We have recently shown that basal unit activity in mPFC is reduced by MS (Stevenson et al., 2008). The present results of attenuated unit and LFP activity with MS confirm and extend these previous findings, suggesting that MS impairs adult mPFC function. We have also previously demonstrated that activity in right mPFC neurons is attenuated with MS in response to FG-7142 (Stevenson et al., 2008), indicating that functionally-relevant alterations in mPFC GABA transmission are mediated by the early environment. This benzodiazepine receptor partial inverse agonist induces various behavioral and physiological effects which are also elicited by stressors (Pellow and File, 1985, 1986; Murphy et al., 1996; Dazzi et al., 2001). Thus the results presented here confirm our previous findings and lend further support to the suggestion that FG-7142 may be useful in modeling certain aspects of mPFC dysfunction induced by stressors (Stevenson et al., 2007, 2008). Moreover, these results may also model early environmental programming of stress reactivity in adulthood by mediating lateralized activation and hemispheric coupling of mPFC function.

The finding of increased neuronal activity in MPFC with FG-7142 is congruent with evidence from in vivo electrophysiology (Stevenson et al., 2007, 2008) and Fos labeling (Singewald et al., 2003) studies showing FG-7142-induced neuronal activation in this region. FG-7142 is a partial inverse agonist which acts on the benzodiazepine binding 
site of the $\mathrm{GABA}_{\mathrm{A}}$ receptor. This drug would therefore be expected to decrease inhibition mediated by local GABA interneurons and consequently disinhibit activity in glutamate pyramidal cells (Palmer et al., 1988). In addition to its effects on GABAergic inhibitory tone, FG-7142 also activates other neurotransmitter systems indirectly, including mesocortical dopamine projections (Murphy et al., 1996; Dazzi et al., 2001). Thus it is possible that the effects of FG-7142 on neuronal activity in mPFC observed in the present study are due to both direct and indirect effects on $\mathrm{GABA}_{\mathrm{A}}$ and dopamine receptor signaling in $\mathrm{mPFC}$.

It should be noted that the increase in $\mathrm{MPFC}$ neuronal activity in response to $\mathrm{FG}-7142$ reported here appears to be greater than that reported previously (Stevenson et al., $2007,2008)$. While the reasons for this apparent discrepancy are not obvious, subtle variations in the dosing regimens used in these studies may account for this difference. Although cumulative dosing and i.v. administration were used both here and in our previous studies, the doses used and the interval between successive doses differed. Previously we had shown that, although the lowest dose $(0.33 \mathrm{mg} / \mathrm{kg})$ of FG-7142 increased the activity of mPFC neurons, there was little if any effect of subsequent doses on neuronal activity. In the present study we sought to assess the effects of a lower dose $(0.1 \mathrm{mg} / \mathrm{kg})$ of FG-7142 and a longer interval (5 min) between drug doses than used previously ( $3 \mathrm{~min}$ ) to ensure that FG-7142 had sufficient time to exert its effect. Compared to our previous studies, the present results suggest that a lower $(0.1 \mathrm{mg} /$ $\mathrm{kg}$ ) initial dose of FG-7142 has a greater effect on mPFC activity compared to a higher $(0.33 \mathrm{mg} / \mathrm{kg})$ dose. However, as we observed previously, there was little or no additional effect on neuronal activation with subsequent doses of FG-7142 despite the longer interval used here. We have recently hypothesized that low doses of FG-7142 increase neuronal activity by acting directly on the $\mathrm{GABA}_{\mathrm{A}}$ receptor, whereas higher doses of drug may have opposing effects on neuronal firing via indirect actions on other neuromodulators such as dopamine (Stevenson et al., 2007). Future studies directly comparing the effects of different doses of FG-7142 using both between- and within-subject designs could prove useful in addressing this issue.

Maturation of GABA neurons and their dopamine innervation occurs in mPFC during the postnatal period (Vincent et al., 1995; Benes et al., 1996), suggesting that GABA and dopamine transmission in MPFC are subject to plasticity in early life (Benes et al., 2000). Indeed, the expression of $\mathrm{GABA}_{\mathrm{A}}$ and benzodiazepine receptors in mPFC is reduced by MS (Caldji et al., 2000). Basal levels of dopamine in mPFC are elevated by maternal deprivation (Jezierski et al., 2007), possibly as a consequence of reduced dopamine metabolism (Matthews et al., 2001). Moreover, the early environment may mediate asymmetries in $\mathrm{MPFC}$ neurotransmission and consequently lateralized $\mathrm{mPFC}$ function later in life. While there is a paucity of evidence concerning asymmetry of mPFC GABA transmission (Mora et al., 1984), dopamine transmission in mPFC shows significant lateralization (Slopsema et al., 1982; Carlson et al., 1988). Furthermore, studies have shown that alterations in hemispheric asymmetry of mPFC dopamine transmission are programmed during various developmental stages in early life (Fride and Weinstock, 1988; Brake et al., 2000), including the postnatal period (Zhang et al., 2005; Sullivan and Dufresne, 2006). Thus it is possible that the hemisphere-dependent effects of FG7142 on mPFC activity with different early rearing conditions reported here are due in part to lateralized alterations in dopamine transmission in this region.

Perhaps the most intriguing finding of the present study is that of altered functional coupling between left and right mPFC with different early rearing conditions. Inter-hemispheric communication between mPFC neurons is mediated predominantly by the corpus callosum (CC). Pyramidal cells in left and right mPFC project via the $\mathrm{CC}$ to both pyramidal cells and GABA interneurons in the contralateral hemisphere (Carr and Sesack, 1998). Mesocortical dopamine afferents also synapse with these contralaterally projecting pyramidal neurons (Carr and Sesack, 2000). This anatomical arrangement suggests that GABA and dopamine transmission may regulate left-right mPFC coupling. Interestingly, the early rearing environment has been shown to influence $\mathrm{CC}$ development. Early $\mathrm{H}$ increases the width of the CC (Berrebi et al., 1988). In contrast, a reduction in neuronal number has been observed in the $\mathrm{CC}$ with maternal deprivation (Poeggel et al., 2000). Early life stress also decreases CC size (Sanchez et al., 1998). Taken together with previous findings, the present results indicate that early rearing conditions regulate functionallyrelevant alterations in CC structure later in life (Denenberg et al., 1981). Moreover, it is possible that the differences in hemispheric functional connectivity observed between the early rearing groups in response to FG-7142 are due to the effects of this drug on GABA and dopamine transmission in mPFC.

The mPFC and its dopamine innervation are importantly involved in mediating cognition and executive function and, as such, modulate stress reactivity (Robbins and Roberts, 2007). Behavioral and neuroendocrine responsivity to stressors are regulated by mPFC (Amat et al., 2005, 2006; Diorio et al., 1993; Radley et al., 2006) and mesocortical dopamine projections (Sullivan and Gratton, 1998; Bland et al., 2003). Furthermore, activation of mPFC and dopamine transmission in this region occurs in a lateralized manner in response to stressful stimuli, such that the right hemisphere is thought to play a preferential role in mediating adaptive coping responses to stressors (Sullivan, 2004). Studies have shown that behavioral and neuroendocrine reactivity to stressors is mediated selectively by right mPFC (Sullivan and Gratton 1999, 2002) and mesocortical dopamine afferents to this hemisphere (Carlson et al., 1991, 1993; Sullivan and Szechtman, 1995; Sullivan and Gratton, 1998; Berridge et al., 1999; Thiel and Schwarting, 2001). Thus the role of the early rearing environment in regulating stress reactivity later in life could be mediated by asymmetric alterations in mPFC function.

In the present study, reduced basal unit activity in $\mathrm{mPFC}$ neurons was observed only in the right hemisphere with MS. In response to FG-7142, these animals also 
showed activation of left but not right MPFC neurons. This deficit in right mPFC function with MS could result in impaired adaptive coping responses to stressors which may account, at least in part, for the enhanced vulnerability to stress observed in these animals (Caldji et al., 2000; Huot et al., 2001; Francis et al., 2002; Ladd et al., 2004; Plotsky et al., 2005; Gardner et al., 2005). Furthermore, the finding of selective activation of right mPFC neurons by FG-7142 with $\mathrm{H}$ may model the enhanced resilience to stress seen in these animals (Meaney et al., 1996). Finally, hemispheric synchronization was attenuated by MS and potentiated by $\mathrm{H}$. It is therefore tempting to speculate that early environmental programming of left-right mPFC coupling may also play a role in mediating adaptive or maladaptive coping responses to stressors and, as such, in conferring resilience or vulnerability to stress, respectively. One potentially relevant confound is that the neuronal recordings obtained in the present study were conducted under anesthesia in response to a drug which mimics various effects of stressors. Directly assessing the effects of MS on stress-induced mPFC activity in the freely-behaving animal should prove useful in clarifying this issue.

The present results demonstrate clear differences between $\mathrm{H}$ and $\mathrm{MS}$ on basal activity in $\mathrm{MPFC}$, lateralization of mPFC activity in response to FG-7142, and hemispheric synchronization of mPFC activity. However, while the effects of AFR were similar to $\mathrm{H}$ on some measures (e.g. unit activity and hemispheric coupling under basal conditions), they resembled MS on others (e.g. FG-7142-induced activity). These findings are in general agreement with those reported in previous studies and add to a growing body of evidence suggesting that AFR may represent an intermediate phenotype between $\mathrm{H}$ and MS (Huot et al., 2001; Jaworski et al., 2005; Gustafson and Nylander 2006; Stevenson et al., 2008).

The findings reported here indicate that the early environment programs hemispheric lateralization and synchronization of mPFC function which may impact on stress reactivity in adulthood. These results may help to further elucidate the neurobiological mechanisms by which early adversity enhances the vulnerability to stressors later in life (Heim et al., 2004). The early postnatal period is critical for the development of the brain in general and the frontal lobe in particular (Case, 1992; Thatcher, 1992). Interestingly, evidence obtained from examining changes in intra-hemispheric synchronization throughout childhood indicates that differences in the onset and rate of frontal development are observed between the left and right hemispheres which appear to be functionally relevant (Thatcher et al., 1987). Moreover, childhood abuse or neglect is associated with enhanced HPA reactivity to stressors, decreased frontal cortical volume, abnormal cortical development in the left hemisphere, and reduced CC size in adulthood (Ito et al., 1998; Heim et al., 2000; Teicher et al., 2004; Cohen et al., 2006), suggesting that alterations in asymmetric activation and hemispheric coupling of frontal cortical function may also be mediated by early life stress in humans.
Acknowledgments-The authors would like to thank Clare Spicer for her expert technical assistance. This research was supported by a Marie Curie Incoming International Fellowship and a NARSAD Young Investigator Award to C.W.S. and C.A.M.

\section{REFERENCES}

Amat J, Paul E, Zarza C, Watkins LR, Maier SF (2006) Previous experience with behavioral control over stress blocks the behavioral and dorsal raphe nucleus activating effects of later uncontrollable stress: role of the ventral medial prefrontal cortex. J Neurosci 26:13264-13272.

Amat J, Baratta MV, Paul E, Bland ST, Watkins LR, Maier SF (2005) Medial prefrontal cortex determines how stressor controllability affects behavior and dorsal raphe nucleus. Nat Neurosci 8:365-371.

Amjad AM, Halliday DM, Rosenberg JR, Conway BA (1997) An extended difference of coherence test for comparing and combining several independent coherence estimates: theory and application to the study of motor units and physiological tremor. J Neurosci Methods 73:69-79.

Benes FM, Taylor JB, Cunningham MC (2000) Convergence and plasticity of monoaminergic systems in the medial prefrontal cortex during the postnatal period: implications for the development of psychopathology. Cereb Cortex 10:1014-1027.

Benes FM, Vincent SL, Molloy R, Khan Y (1996) Increased interaction of dopamine-immunoreactive varicosities with GABA neurons of rat medial prefrontal cortex occurs during the postweanling period. Synapse 23:237-245.

Berrebi AS, Fitch RH, Ralphe DL, Denenberg JO, Friedrich VL Jr, Denenberg VH (1988) Corpus callosum: region-specific effects of sex, early experience and age. Brain Res 438:216-224.

Berridge CW, Milton E, Clark W, Roth RH (1999) Engagement in a non-escape (displacement) behavior elicits a selective and lateralized suppression of frontal cortical dopaminergic utilization in stress. Synapse 32:187-197.

Bland ST, Hargrave D, Pepin JL, Amat J, Watkins LR, Maier SF (2003) Stressor controllability modulates stress-induced dopamine and serotonin efflux and morphine-induced serotonin efflux in the medial prefrontal cortex. Neuropsychopharmacology 28:1589-1596.

Brake WG, Sullivan RM, Gratton A (2000) Perinatal distress leads to lateralized medial prefrontal cortical dopamine hypofunction in adult rats. J Neurosci 20:5538-5543.

Bullock T (1997) Signals and signs in the nervous system: The dynamic anatomy of electrical activity is probably information-rich. Proc Natl Acad Sci USA 94:1-6.

Caldji C, Francis D, Sharma S, Plotsky PM, Meaney MJ (2000) The effects of early rearing environment on the development of GABAA and central benzodiazepine receptor levels and novelty-induced fearfulness in the rat. Neuropsychopharmacology 22:219-229.

Calhoun JB (1962) The ecology and sociology of the Norway rat. Betheseda, MD: Department of Health, Education and Welfare, Public Health Service Document No. 1008.

Carlson JN, Fitzgerald LW, Keller RW Jr, Glick SD (1991) Side and region dependent changes in dopamine activation with various durations of restraint stress. Brain Res 550:313-318.

Carlson JN, Fitzgerald LW, Keller RW, Glick SD (1993) Lateralized changes in prefrontal cortical dopamine activity induced by controllable and uncontrollable stress in the rat. Brain Res 630: 178-187.

Carlson JN, Glick SD, Hinds PA, Baird JL (1988) Food deprivation alters dopamine utilization in the rat prefrontal cortex and asymmetrically alters amphetamine-induced rotational behavior. Brain Res 454:373-377.

Carr DB, Sesack SR (2000) Dopamine terminals synapse on callosal projection neurons in the rat prefrontal cortex. J Comp Neurol 425:275-283. 
Carr DB, Sesack SR (1998) Callosal terminals in the rat prefrontal cortex: synaptic targets and association with GABA-immunoreactive structures. Synapse 29:193-205.

Case R (1992) The role of the frontal lobes in the regulation of cognitive development. Brain Cogn 20:51-73.

Cohen RA, Grieve S, Hoth KF, Paul RH, Sweet L, Tate D, Gunstad J, Stroud L, McCaffery J, Hitsman B, Niaura R, Clark CR, MacFarlane A, Bryant R, Gordon E, Williams LM (2006) Early life stress and morphometry of the adult anterior cingulate cortex and caudate nuclei. Biol Psychiatry 59:975-982.

Dazzi L, Spiga F, Pira L, Ladu S, Vacca G, Rivano A, Jentsch JD, Biggio G (2001) Inhibition of stress- or anxiogenic-drug-induced increases in dopamine release in the rat prefrontal cortex by longterm treatment with antidepressant drugs. J Neurochem 76:12121220.

Denenberg VH, Zeidner L, Rosen GD, Hofmann M, Garbanati JA, Sherman GF, Yutzey DA (1981) Stimulation in infancy facilitates interhemispheric communication in the rabbit. Brain Res 227: 165-169.

Diggle PJ (1990) Spectral analysis. In: Time series. A biostatistical introduction (Diggle PJ, ed), pp 94-133 New York: Oxford University Press.

Diorio D, Viau V, Meaney MJ (1993) The role of the medial prefrontal cortex (cingulate gyrus) in the regulation of hypothalamic-pituitaryadrenal responses to stress. J Neurosci 13:3839-3847.

Dorow R, Horowski R, Paschelke G, Amin M (1983) Severe anxiety induced by FG 7142, a beta-carboline ligand for benzodiazepine receptors. Lancet 2:98-99.

Farmer SF, Gibbs J, Halliday DM, Harrison LM, James LM, Mayston MJ, Stephens JA (2007) Changes in EMG coherence between long and short thumb abductor muscles during human development. J Physiol 579:389-402.

Francis DD, Diorio J, Plotsky PM, Meaney MJ (2002) Environmental enrichment reverses the effects of maternal separation on stress reactivity. J Neurosci 22:7840-7843.

Fride E, Weinstock M (1988) Prenatal stress increases anxiety related behavior and alters cerebral lateralization of dopamine activity. Life Sci 42:1059-1065.

Gabbott PL, Dickie BG, Vaid RR, Headlam AJ, Bacon SJ (1997) Local-circuit neurones in the medial prefrontal cortex (areas 25, 32 and 24b) in the rat: morphology and quantitative distribution. J Comp Neurol 377:465-499.

Gardner KL, Thrivikraman KV, Lightman SL, Plotsky PM, Lowry CA (2005) Early life experience alters behavior during social defeat: focus on serotonergic systems. Neuroscience 136:181-191.

Gartside SE, Johnson DA, Leitch MM, Troakes C, Ingram CD (2003) Early life adversity programs changes in central 5-HT neuronal function in adulthood. Eur J Neurosci 17:2401-2408.

Green JD (1958) A simple microelectrode for recording from the central nervous system. Nature 182:962.

Gronier BS, Rasmussen K (2003) Electrophysiological effects of acute and chronic olanzapine and fluoxetine in the rat prefrontal cortex. Neurosci Lett 349:196-200.

Gustafsson L, Nylander I (2006) Time-dependent alterations in ethanol intake in male Wistar rats exposed to short and prolonged daily maternal separation in a 4-bottle free-choice paradigm. Alcohol Clin Exp Res 30:2008-2016.

Halliday DM, Rosenberg JR, Amjad AM, Breeze P, Conway BA, Farmer SF (1995) A framework for the analysis of mixed time series/point process data - theory and application to the study of physiological tremor, single motor unit discharges and electromyograms. Prog Biophys Mol Biol 64:237-278.

Hart S, Sarter M, Bernston GG (1998) Cardiovascular and somatic startle and defense: concordant and discordant actions of benzodiazepine receptor agonists and inverse agonists. Behav Brain Res 90:175-186.
Heim C, Plotsky PM, Nemeroff CB (2004) Importance of studying the contributions of early adverse experience to neurobiological findings in depression. Neuropsychopharmacology 29:641-648.

Heim C, Newport DJ, Heit S, Graham YP, Wilcox M, Bonsall R, Miller AH, Nemeroff CB (2000) Pituitary-adrenal and autonomic responses to stress in women after sexual and physical abuse in childhood. JAMA 284:592-597.

Helmeke C, Ovtscharoff W Jr, Poeggel G, Braun K (2008) Imbalance of immunohistochemically characterized interneuron populations in the adolescent and adult rodent medial prefrontal cortex after repeated exposure to neonatal separation stress. Neuroscience $152: 18-28$.

Helmeke C, Ovtscharoff W Jr, Poeggel G, Braun K (2001a) Juvenile emotional experience alters synaptic inputs on pyramidal neurons in the anterior cingulate cortex. Cereb Cortex 11:717-727.

Helmeke C, Poeggel G, Braun K (2001b) Differential emotional experience induces elevated spine densities on basal dendrites of pyramidal neurons in the anterior cingulate cortex of Octodon degus. Neuroscience 104:927-931.

Homayoun H, Jackson ME, Moghaddam B (2005) Activation of metabotropic glutamate $2 / 3$ receptors reverses the effects of NMDA receptor hypofunction on prefrontal cortex unit activity in awake rats. J Neurophysiol 93:1989-2001.

Huot RL, Thrivikraman KV, Meaney MJ, Plotsky PM (2001) Development of adult ethanol preference and anxiety as a consequence of neonatal maternal separation in Long Evans rats and reversal with antidepressant treatment. Psychopharmacology 158:366-373.

Ito Y, Teicher MH, Glod CA, Ackerman E (1998) Preliminary evidence for aberrant cortical development in abused children: a quantitative EEG study. J Neuropsychiatry Clin Neurosci 10:298-307.

Jackson ME, Homayoun H, Moghaddam B (2004) NMDA receptor hypofunction produces concomitant firing rate potentiation and burst activity reduction in the prefrontal cortex. Proc Natl Acad Sci U S A 101:8467-8472.

Jaworski JN, Francis DD, Brommer CL, Morgan ET, Kuhar MJ (2005) Effects of early maternal separation on ethanol intake, GABA receptors and metabolizing enzymes in adult rats. Psychopharmacology 181:8-15.

Jezierski G, Zehle S, Bock J, Braun K, Gruss M (2007) Early stress and chronic methylphenidate cross-sensitize dopaminergic responses in the adolescent medial prefrontal cortex and nucleus accumbens. J Neurochem 103:2234-2244.

Jung M, Qin Y, McNaughton B, Barnes C (1998) Firing characteristics of deep layer neurons in prefrontal cortex in rats performing spatial working memory tasks. Cereb Cortex 8:437-450.

Ladd CO, Huot RL, Thrivikraman KV, Nemeroff CB, Plotsky PM (2004) Long-term adaptations in glucocorticoid receptor and mineralocorticoid receptor mRNA and negative feedback on the hypothalamopituitary-adrenal axis following neonatal maternal separation. Biol Psychiatry 55:367-375.

Laviolette SR, Lipski WJ, Grace AA (2005) A subpopulation of neurons in the medial prefrontal cortex encodes emotional learning with burst and frequency codes through a dopamine D4 receptor-dependent basolateral amygdala input. J Neurosci 25:6066-6075.

Macri S, Würbel H (2006) Developmental plasticity of HPA and fear responses in rats: a critical review of the maternal mediation hypothesis. Horm Behav 50:667-680.

Martijena ID, Rodríguez Manzanares PA, Lacerra C, Molina VA (2002) Gabaergic modulation of the stress response in frontal cortex and amygdala. Synapse 45:86-94.

Matthews K, Dalley JW, Matthews C, Tsai TH, Robbins TW (2001) Periodic maternal separation of neonatal rats produces region- and gender-specific effects on biogenic amine content in postmortem adult brain. Synapse 40:1-10.

Matthews K, Robbins TW, Everitt BJ, Caine SB (1999) Repeated neonatal maternal separation alters intravenous cocaine self-administration in adult rats. Psychopharmacology 141:123-134. 
Matthews K, Wilkinson LS, Robbins TW (1996) Repeated maternal separation of preweanling rats attenuates behavioral responses to primary and conditioned incentives in adulthood. Physiol Behav 59:99-107.

Meaney MJ, Diorio J, Francis D, Widdowson J, LaPlante P, Caldji C, Sharma S, Seckl JR, Plotsky PM (1996) Early environmental regulation of forebrain glucocorticoid receptor gene expression: implications for adrenocortical responses to stress. Dev Neurosci 18:49-72.

Mora F, Peinado JM, Myers RD (1984) Symmetrical distribution of amino acid neurotransmitters in the right and left cerebral cortex of the rat. Neurochem Res 9:1109-1115.

Murphy BL, Arnsten AF, Jentsch JD, Roth RH (1996) Dopamine and spatial working memory in rats and monkeys: pharmacological reversal of stress-induced impairment. J Neurosci 16:7768-7775.

Palmer MR, van Horne CG, Harlan JT, Moore EA (1988) Antagonism of ethanol effects on cerebellar Purkinje neurons by the benzodiazepine inverse agonists Ro 15-4513 and FG 7142: electrophysiological studies. J Pharmacol Exp Ther 247:1018-1024.

Paxinos G, Watson C (1997) The rat brain in stereotaxic coordinates, 3rd edition. New York: Academic Press.

Pellow S, File SE (1986) Anxiolytic and anxiogenic drug effects on exploratory activity in an elevated plus-maze: a novel test of anxiety in the rat. Pharmacol Biochem Behav 24:525-529.

Pellow S, File SE (1985) The effects of putative anxiogenic compounds (FG 7142, CGS 8216 and Ro 15-1788) on the rat corticosterone response. Physiol Behav 35:587-590.

Plotsky PM, Thrivikraman KV, Nemeroff CB, Caldji C, Sharma S, Meaney MJ (2005) Long-term consequences of neonatal rearing on central corticotropin-releasing factor systems in adult male rat offspring. Neuropsychopharmacology 30:2192-2204.

Poeggel G, Hasse C, Gulyaeva N, Braun K (2000) Quantitative changes in reduced nicotinamide adenine dinucleotide phosphatediaphorase-reactive neurons in the brain of Octodon degus after periodic maternal separation and early social isolation. Neuroscience 99:381-387.

Radley JJ, Arias CM, Sawchenko PE (2006) Regional differentiation of the medial prefrontal cortex in regulating adaptive responses to acute emotional stress. J Neurosci 26:12967-12976.

Robbins TW, Roberts AC (2007) Differential regulation of fronto-executive function by the monoamines and acetylcholine. Cereb Cortex 17 (Suppl 1):i151-i160.

Robinson DA (1968) The electrical properties of metal electrodes. Proc IEEE 56:1065-1071.

Rosenberg JR, Amjad AM, Breeze P, Brillinger DR, Halliday DM (1989) The Fourier approach to the identification of functional coupling between neuronal spike trains. Prog Biophys Mol Biol 53:1-31.

Sanchez MM, Hearn EF, Do D, Rilling JK, Herndon JG (1998) Differential rearing affects corpus callosum size and cognitive function of rhesus monkeys. Brain Res 812:38-49.

Sesack SR, Bunney BS (1989) Pharmacological characterization of the receptor mediating electrophysiological responses to dopamine in the rat medial prefrontal cortex: a microiontophoretic study. J Pharmacol Exp Ther 248:1323-1333.

Singewald N, Salchner P, Sharp T (2003) Induction of c-Fos expression in specific areas of the fear circuitry in rat forebrain by anxiogenic drugs. Biol Psychiatry 53:275-283.

Slopsema JS, van der Gugten J, de Bruin JP (1982) Regional concentrations of noradrenaline and dopamine in the frontal cortex of the rat: dopaminergic innervation of the prefrontal subareas and lateralization of prefrontal dopamine. Brain Res 250:197-200.

Snodderly DM Jr (1973) Extracellular single unit recording. In: Bioelectric recording techniques, part A. Cellular processes and brain potentials (Thompson RF, Patterson MM, eds), pp 137-163. New York: Academic Press.

Steriade M (1997) Synchronized activities of coupled oscillators in the cerebral cortex and thalamus at different levels of vigilance. Cereb Cortex 7:583-604.

Stevenson CW, Marsden CA, Mason R (2008) Early life stress causes FG-7142-induced corticolimbic dysfunction in adulthood. Brain Res 1193:43-50.

Stevenson CW, Halliday DH, Marsden CA, Mason R (2007) Systemic administration of the benzodiazepine receptor partial inverse agonist FG-7142 disrupts corticolimbic network interactions. Synapse 61:646-663.

Sullivan RM, Dufresne MM (2006) Mesocortical dopamine and HPA axis regulation: role of laterality and early environment. Brain Res 1076:49-59.

Sullivan RM (2004) Hemispheric asymmetry in stress processing in the rat: role of mesocortical dopamine. Stress 7:131-143.

Sullivan RM, Gratton A (2002) Behavioral effects of excitotoxic lesions of ventral medial prefrontal cortex in the rat are hemisphere-dependent. Brain Res 927:69-79.

Sullivan RM, Gratton A (1999) Lateralized effects of medial prefrontal cortex lesions on neuroendocrine and autonomic stress responses in rats. J Neurosci 19:2834-2840.

Sullivan RM, Gratton A (1998) Relationships between stress-induced increases in medial prefrontal cortical dopamine and plasma corticosterone levels in rats: role of cerebral laterality. Neuroscience 83:81-91.

Sullivan RM, Szechtman H (1995) Asymmetrical influence of mesocortical dopamine depletion on stress ulcer development and subcortical dopamine systems in rats: implications for psychopathology. Neuroscience 65:757-766.

Tan H, Zhong P, Yan Z (2004) Corticotropin-releasing factor and acute stress prolongs serotonergic regulation of GABA transmission in prefrontal cortical pyramidal neurons. J Neurosci 24:5000-5008.

Teicher MH, Dumont NL, Ito Y, Vaituzis C, Giedd JN, Andersen SL (2004) Childhood neglect is associated with reduced corpus callosum area. Biol Psychiatry 56:80-85.

Thatcher RW (1992) Cyclic cortical reorganization during early childhood. Brain Cogn 20:24-50.

Thatcher RW, Walker RA, Giudice S (1987) Human cerebral hemispheres develop at different rates and ages. Science 236: 1110-1113.

Thiel CM, Schwarting RK (2001) Dopaminergic lateralisation in the forebrain: relations to behavioural asymmetries and anxiety in male Wistar rats. Neuropsychobiology 43:192-199.

Vincent SL, Pabreza L, Benes FM (1995) Postnatal maturation of GABA-immunoreactive neurons of rat medial prefrontal cortex. J Comp Neurol 355:81-92.

Yuan J, Manabe S (1996) Evaluation of exposure level of N-methylbeta-carboline-3-carboxamide (FG 7142), an anxiogenic agent in humans. Environ Pollut 94:267-271.

Zhang TY, Chrétien P, Meaney MJ, Gratton A (2005) Influence of naturally occurring variations in maternal care on prepulse inhibition of acoustic startle and the medial prefrontal cortical dopamine response to stress in adult rats. J Neurosci 25:1493-1502. 